\title{
Horta Teatro: corpo, palavra e espaço
}

\author{
Giselly Brasil ${ }^{1}$ \\ Gabriel Webber ${ }^{2}$ \\ Ligia Storalli3
}

Submetido em: 04/03/2020

Aprovado em: 17/04//2020

\section{DOI: $10.5965 / 2358092521232020258$}

\footnotetext{
1 Doutora em Artes - Artes Cênicas/Theaterwissenschaft (Universidade de São Paulo e Universidade de Giessen, na Alemanha). Professora do curso de Artes da Universidade Federal do Paraná (UFPR). E-mail: gisellybrasilw@gmail.com

2 Acadêmico da graduação em Licenciatura em Artes (UFPR). Bacharel em Gestão Ambiental e Especialista em Educação Ambiental com Ênfase em Espaços Educadores Sustentáveis (UFPR). E-mail: gabrielwebb@gmail.com

3 Acadêmica da graduação em Licenciatura em Artes (UFPR). E-mail: ligiastoralli@gmail.com
} 


\section{RESUMO}

Este texto é um relato de experiência do Projeto Horta Teatro. O projeto acontece na interface entre arte e educação e tem como objetivo promover experiências sensíveis a partir de práticas que estimulam relações entre corpo, espaço e palavra. Ativar o olhar e a percepção para o entorno é intervir no ambiente, é produzir possibilidades de diálogo com o meio. No processo educativo aqui proposto a produção de arte se fundamenta em práticas de corpo e movimento, experimentos teatrais e leituras que acontecem em diferentes espaços. 0 ponto de encontro é o espaço em torno de uma horta cultivada pelos participantes. As experiências aqui relatadas são ações poéticas que surgiram a partir de elementos da escrita do poeta Manoel de Barros. A palavra aparece no mundo como disparadora de sentidos e sensações. Potencialidades da palavra e do corpo foram experimentadas em diferentes processos de criação e intervenções poéticas.

Palavras-chave: corpo, espaço, palavra, intervenções poéticas.

\section{ABSTRACT}

This text is a report of the Garden Theatre Project's experience. The project takes place at the interface between art and education and it aims to promote sensitive experiences based on practices that stimulate relationships between body, space and word. Activating the look and perception to the environment is to intervene in it, it is to produce possibilities of dialogue with the space around. In the educational process proposed here, art production is based on body and movement practices, theatrical experiments and readings that take place in different spaces. The meeting point is the space around a garden cultivated by the participants. The experiences reported here are poetic actions that emerged 
from element of the poet Manoel de Barros's writing. The word appears in the world as a trigger for senses and sensations. Potentialities of the word and the body were experienced in different processes of creation and poetic interventions.

Keywords: body, space, word, poetic interventions.

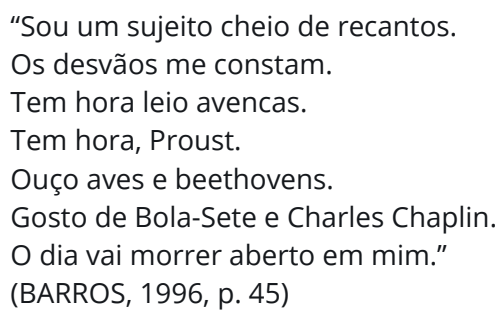

O projeto Horta Teatro ${ }^{4}$ acontece desde o início de 2018 na Universidade Federal do Paraná. A cada semestre ele é composto por um novo grupo e acontece a partir de interesses apresentados pelos integrantes. Como associar Horta e Teatro? Como abordar tais conceitos? O que as pessoas presentes desejam realizar neste contexto provocativo que aproxima Horta e Teatro? O que o espaço da Horta provoca nas relações entre os participantes? Como pensar a prática teatral como evento que ativa espaços e dinamiza a percepção? Os encontros são orientados pela escuta, pelo diálogo, pelo desafio de criar relações com a arquitetura e com espaços esquecidos na área da Universidade. As práticas e as discussões coletivas orientam as propostas e os trabalhos de cada semestre. Assim, o projeto é construído sempre a partir de impulsos, desejos, leituras e provocações.

Os encontros acontecem às quartas-feiras em um espaço

40 Projeto Horta Teatro é coordenado pela professora Giselly Brasil e oferecido como proposta educativa no espaço curricular ICH - Interações Culturais e Humanísticas. O trabalho aqui apresentado é uma produção do projeto de iniciação científica Arte Contemporânea e Educação, também coordenado pela docente e do qual participam os pesquisadores Gabriel Webber e Lígia de Mello. Ambos os projetos estão vinculados ao Curso de Artes da Universidade Federal do Paraná. 
curricular chamado de $\mathrm{ICH}^{5}$ (Interações Culturais e Humanísticas). As práticas do Horta Teatro são divididas em dois momentos. No primeiro, o grupo se dedica à construção e ao cultivo de uma horta ao mesmo tempo em que participa de conversas e práticas de sensibilização em torno dela. Os encontros nesse micro espaço da horta e sua dimensão sensível do toque, do cheiro, da visão e do paladar potencializam estímulos no campo do afeto, da experiência e da partilha. O segundo momento, tem como foco práticas de corpo e o mapeamento de estímulos e espaços para a produção de ações poéticas.

No segundo semestre de 2018, o Projeto Horta Teatro se envolveu em travessias pelas obras de Manoel de Barros, horta orgânica e experimentações com a técnica de Viewpoints ${ }^{6}$ - a partir da qual o grupo trabalhou com práticas de improvisação que estimulam a criação de relações temporais e espaciais pautadas na escuta e em respostas cinestésicas. Os processos culminaram na criação de uma intervenção coletiva, a qual foi apresentada no Festival de Interações Culturais e Humanísticas (FICH), que ocorre todo final de semestre. A ação coletiva aconteceu a partir da construção de espaços e intervenções poéticas. Apresentaremos aqui algumas delas: pise na grama descalço e escuta poética, blocos de poesia concreta, viewpoints na horta e folhas bordadas.

Outra ação importante do projeto foi o experimento palavra na horta. Nesta proposta expandimos o nosso campo de ação e fomos experimentar a palavra de Manoel de Barros em um horta de orgânicos numa região rural da cidade. Lá experimentamos relações entre arte e educação em práticas que de-

5"ICH são atividades que promovem a interação vertical (estudantes em fases diferentes dos cursos) e horizontal (estudantes de cursos diferentes no mesmo espaço). Os saberes são problematizados, fortalecendo compromissos éticos e políticos, visando à vivência e o adensamento de relações autogestionárias." (UFPR, 2008, on-line).

6 A técnica do Viewpoints se refere aqui às práticas desenvolvidas pela diretora teatral Anne Bogart, que aborda princípios do movimento através do tempo e do espaço, e que são assim divididos: Viewpoints de Tempo: tempo, resposta cinestésica, duração e repetição e Viewpoints de espaço: topografia, forma, gesto, relação espacial e arquitetura. O principal objetivo do trabalho com essa metodologia é estimular a improvisação, o jogo e a construção de relações inusitadas com diferentes estímulos e elementos. 
safiam limites institucionais.

\section{PONTO DE ENCONTRO}

No semestre aqui relatado, o Projeto Horta Teatro teve como objetivo experimentar a poesia de Manoel de Barros em processos de criação que ocorreram, em sua maioria, nos arredores de uma horta que havia sido construída no semestre anterior por um grupo de alunos dos cursos de artes, agroecologia, turismo, saúde coletiva e gestão e empreendedorismo. O grupo escolheu o local para a criação da horta após um mapeamento de toda a área da Universidade. Visitamos espaços escondidos, observamos a circulação das pessoas, conhecemos plantas, cheiros e sabores que compõem a paisagem na qual estamos inseridos em nosso cotidiano no campus. Feita a pesquisa prática e sensorial, decidimos pelo local onde seria construída a horta que foi montada em caixas de madeira produzidas por funcionários da universidade que contribuíram com o projeto. A horta foi criada na primeira ação do projeto e segue sendo cultivada por novos integrantes a cada semestre.

Começamos então o segundo semestre de 2018 em nosso ponto de encontro: a horta, um espaço que fica nas bordas entre o panorama institucional dado pela configuração do prédio que prevê as aulas em ambientes fechados e a construção de uma zona educativa poética ao ar livre na Universidade.

Buscamos a poesia como ponto de partida. Foi consenso o mergulho nos poemas de Manoel de Barros, para explorarmos a palavra, saboreá-la. Manoel nos ajudou a perceber as miudezas, a dar respeito às coisas desimportantes. As palavras surgiram como estímulos para observar e reinventar o cotidiano no espaço e no corpo. Assim, tínhamos como elementos: as palavras, os corpos e a horta.

As palavras saltavam dos livros, das poesias escritas pelo poeta e aos poucos se imprimiam no mundo. Palavra dita em voz alta, palavra sussurrada, palavra pintada no concreto, palavra bordada em folhas de árvores. Experimentamos a palavra em sua materialidade, em sua sonoridade e em partituras cor- 
porais. A palavra que percorre o corpo, que agita os sentidos e cria novas relações com o meio.

Os corpos experimentaram possibilidades de relação com o outro, com o ambiente e com a escrita de Manoel de Barros. As palavras eram ditas enquanto corpos se estendiam pela grama, enquanto mapeavam relações com a arquitetura e respondiam aos estímulos do meio. Experimentamos o corpo em contato com a terra e com o concreto. Exercitamos um corpo- escuta, um corpo atento às informações e às miudezas que compõem a paisagem.

Pensávamos na ativação de espaços ociosos e ampliamos o campo de ação da horta. Estendemos as nossas práticas para o entorno da horta e passamos a ocupar um espaço mais amplo e de pouca circulação na universidade.

Como transformar esse lugar? Começamos fazendo modificações na estrutura física, colocando pallets com almofadas, que foram confeccionadas pelos participantes, uma mesinha, que foi encontrada na rua por um dos integrantes, e plantas. No decorrer do processo percebemos que a nossa presença constante ali era um grande ativador do espaço. Mesmo o corpo cotidiano, parado, sentado, lendo, partilhando alimentos, ativava o espaço. Observamos ao longo do semestre cada vez mais pessoas frequentando os arredores da horta. Um lugar que era agora espaço de convivência, borda que confunde os limites institucionais e que modifica as relações previstas.

\section{INTERVENÇÕES POÉTICAS}

A partir das práticas de leitura de poemas de Manoel de Barros experimentamos a palavra em diferentes situações e relações ambientais e, a partir daí, criamos diferentes trabalhos. Essas leituras possibilitaram experimentar a palavra no corpo e também no ambiente, em objetos, na arquitetura e em composições espaciais.

A principal metodologia utilizada para os experimentos relacionados às leituras foi a técnica de Viewpoints, que prevê a escuta e a percepção como elementos fundamentais da criação. 
corpo reage ao meio, é impulsionado por sonoridades e elementos que compõem o espaço. Neste caso, relações espaciais e respostas cinestésicas ampliam as capacidades perceptivas e promovem o surgimento de novas organizações e sentidos. 0 corpo está atento ao meio, responde à ele e experimenta diferentes possibilidades relacionais.

Após inúmeras práticas, passamos a organizar o material produzido criando uma sequência de ações poéticas que seriam compartilhadas com o público no final do semestre. Nosso intuito era construir propostas que pudessem provocar a ação do espectador. Queríamos criar oportunidades para experimentações nas quais todos pudessem participar, aqueles que estavam propondo e aqueles que vinham conhecer o trabalho. A ideia era criar um espaço de troca no qual as propostas se apresentassem como convite para a construção de novas relações e sentidos.

Uma dessas experimentações intitulou-se como pise na grama descalço e escuta poética. Este espaço poético era composto por três caixas de feira em madeira pintadas em vermelho e com estêncil da frase "pise na grama descalço" na cor amarela. As caixas foram preenchidas com terra e plantou-se um tipo de grama conhecida como grama preta, nome científico Ophiopogon japonicus. Três integrantes do Horta Teatro escolheram poesias completas ou trechos de obras de Manoel de Barros e os escreveram à mão em cadernos confeccionados durante os encontros. Com essa experiência nos aproximamos da poética do autor, já que ele também produzia os próprios cadernos (KISHI, 2016). Dessa forma, no FICH os participantes convidaram os espectadores para que se sentassem em cadeiras colocadas uma de frente para a outra de forma que as caixas ficassem entre os participantes (Figura 1). 


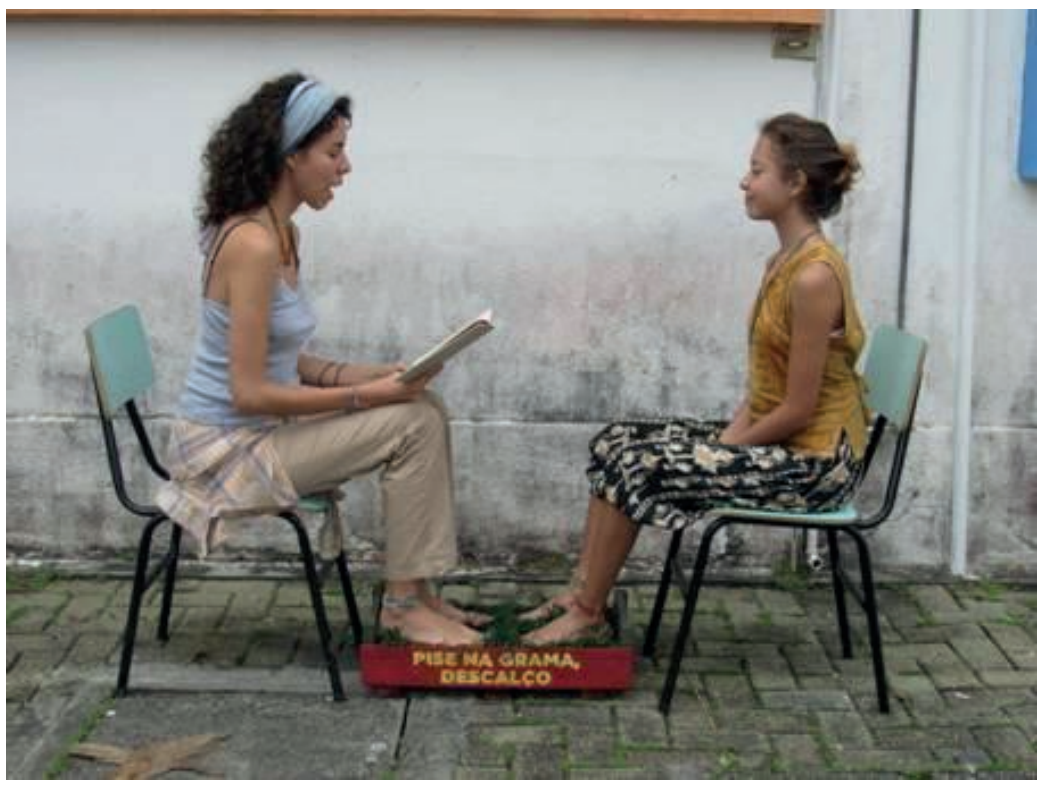

Figura 1

Fonte: Os autores (2018)

Desse modo, as pessoas com os pés descalços nas caixas em contato com a grama preta escutavam as poesias, num ambiente de acolhimento e intimidade, construído pela grama, pelos pés descalços, pelos olhos, ouvidos e voz de quem se prontificava à ação poética compartilhada. Ocorria, em alguns casos, a inversão dos papéis de atuante e espectador, isso quando o participante escutava atentamente e, logo em seguida, contava uma história ou falava uma poesia. Nesse momento, os limites entre propositor e espectador desapareciam, seus corpos se entrelaçavam e ativavam aquele espaço esquecido da universidade. Os corpos passavam a compor uma arquitetura viva e vibrante que avançava da ação poética proposta para o ambiente. Os pés descalços sobre a grama e as palavras que eram trocadas entre os corpos reconfiguravam o espaço. O prédio, 
se somava ao ato gerado pelos corpos em ação. Corpo e concreto criavam agora uma paisagem capaz de transpor barreiras e incentivar um olhar sensível no qual diferentes elementos se somam e dialogam entre si.

Outro espaço poético do Horta Teatro foi formado pelos blocos de poesia concreta. O trabalho constituiu-se de blocos, tipo paver, nos quais pintamos palavras - de poesias selecionadas de Manoel de Barros - nos bloquetes (Figura 2). As palavras, para Jorge Larrosa Bondía (2002), funcionam como potentes mecanismos de subjetivação, elas criam realidades, produzem sentido. Larossa acredita no poder da palavra, em sua força e afirma que tanto fazemos coisas com as palavras como as palavras fazem coisas conosco. O autor afirma ainda que pensamos com palavras e não com pensamentos "e pensar não é somente 'raciocinar' ou 'calcular' ou 'argumentar', como nos tem sido ensinado muitas vezes, mas é sobretudo dar sentido ao que somos e ao que nos acontece" (BONDíA, 2002, p. 21). Na criação dos blocos de poesia concreta observou-se a relação estética dos espectadores na ação experimental com a manipulação dos blocos. Desconstruíam as frases das poesias e formavam outras frases, coerentes ou incoerentes, mas que se impregnavam de sentido para aqueles que as formulavam. Nesse jogo de construção de sentidos Barros nos aponta a potencialidade dessa brincadeira quando nos diz que a "palavra poética tem que chegar ao grau de brinquedo para ser séria" (BARROS, 1996, p. 71). 


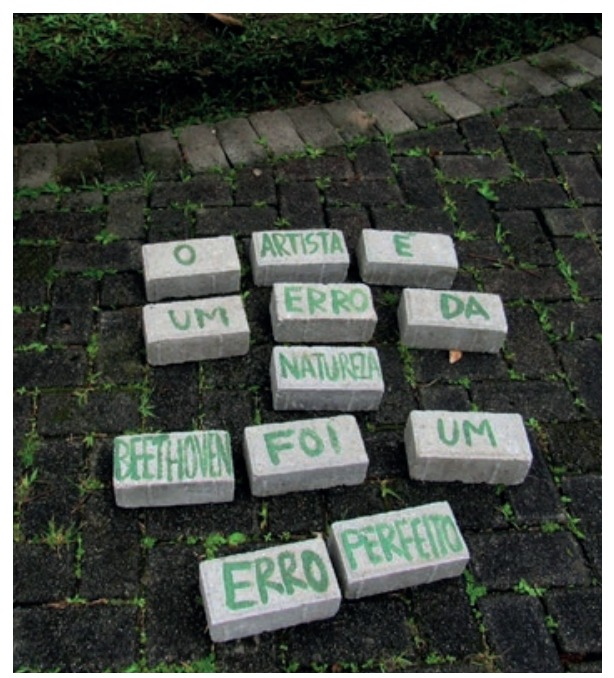

Figura 2

Fonte: Os autores (2018)

Os espectadores e agora brincantes articulavam os blocos de poesia concreta e experimentavam novas relações entre as palavras. Mais do que uma forma representativa, as palavras ganhavam potencialidade no mundo. Formavam e deformavam a gramática daquele espaço vivencial. As palavras manipuladas pelos corpos produziam uma poesia concreta, tridimensional que interferia na composição e percepção do espaço. Novas pontes de comunicação eram elaboradas a partir dessa experimentação que provocava o objeto e a construção de sentidos.

A ação poética viewpoints na horta (Figura 3), foi uma proposta de improvisação baseada em alguns trechos de poesias de Manoel de Barros. Os espectadores circulavam em volta da horta e os integrantes improvisavam a partir de estímulos como a arquitetura do local, velocidade, resposta cinestésica e espaço relacional (RINALDI, 2013). 


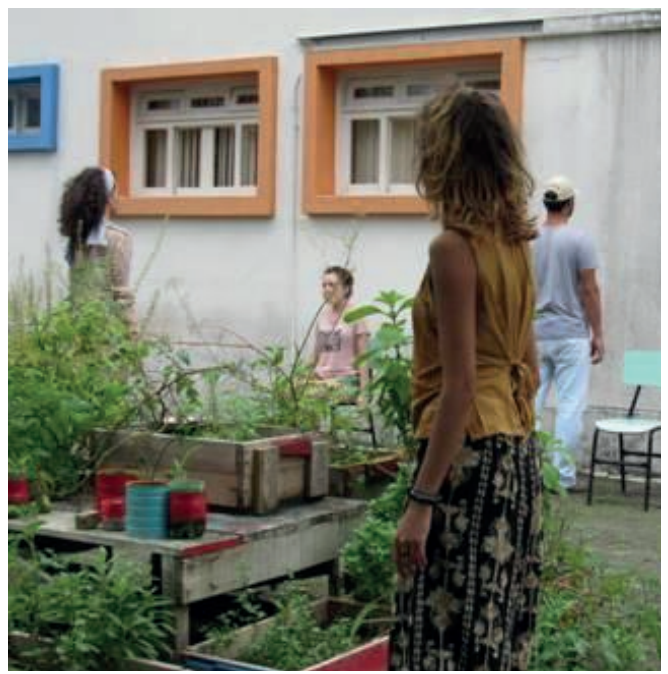

Figura 3

Fonte: Os autores (2018)

No FICH os jogadores do Viewpoints experimentavam a memória cinestésica dos encontros passados e articulavam com o momento presente, com a arquitetura e com os espectadores. Palavras e trechos eram falados conforme o jogo ocorria. Algumas relações se estabeleciam quando os artistas ofereciam às pessoas chá, servido em canecas. Os estímulos sensoriais eram compartilhados num jogo sensível no qual corpo, movimento e escuta ativavam a construção de uma paisagem sonora e gestual.

Outra ação poética que aconteceu neste contexto foi o trabalho bordado em folhas, no qual palavras foram bordadas em folhas de árvores (Figura 4). Alguns integrantes do Horta Teatro bordaram essas palavras em folhas, a partir de poemas de Manoel de Barros, e as colocaram em um cesto. O trabalho ficou à disposição dos espectadores para que pudessem manipular e criar suas composições poéticas. Um grupo de crianças, que esteve presente na apresentação, passou muito tempo experi- 
mentando possibilidades para a composição com as palavras-folhas. Vários desenhos foram criados a partir dos formatos e contornos das folhas ao mesmo tempo em que as palavras se encaixavam e produziam novos sentidos para as palavras do poeta Manoel.

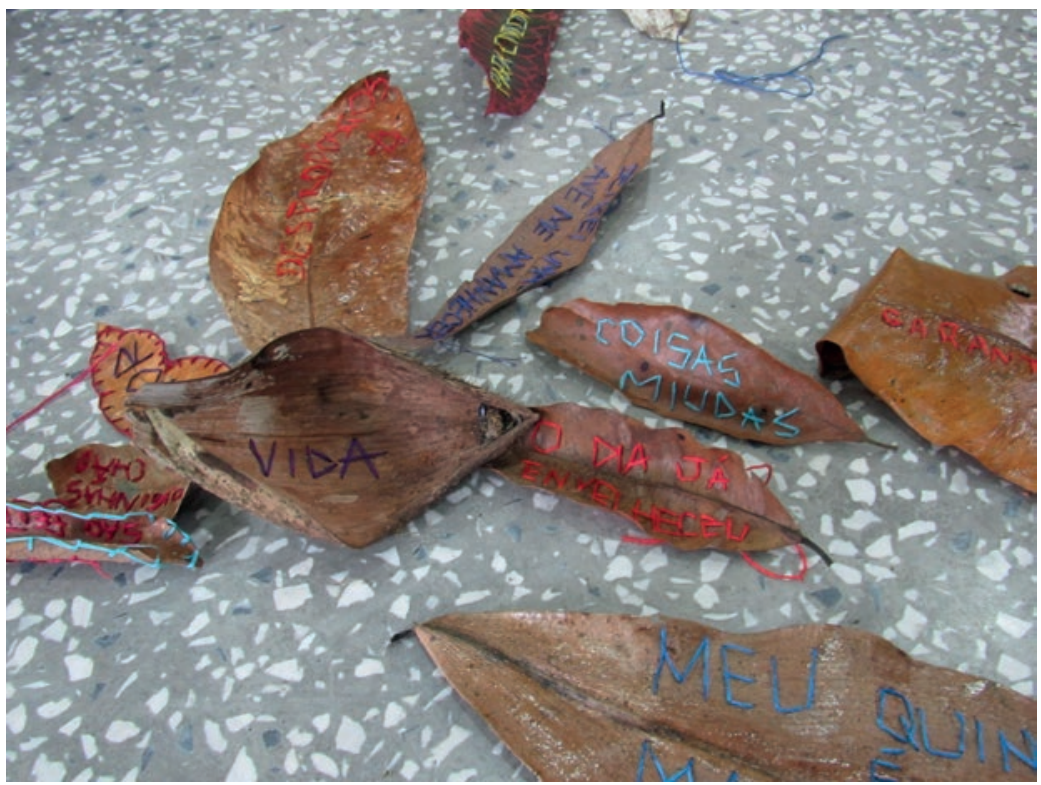

Figura 4

Fonte: Os autores (2018)

Na experiência que trazemos aqui, o espaço da horta se manteve como ponto de encontro, cultivo e partilha do grupo, embora as ações já tivessem se expandido para os arredores da horta. A partir de conversas, cafés e reflexões o campo de ação foi se ampliando ainda mais. Queríamos caminhar, descobrir trajetos, percorrer territórios. Passamos a observar o nosso entorno e as possibilidades de descoberta de espaços para 
além da Universidade. O campus fica na cidade de Matinhos, no litoral do Paraná. E para além do campus, há montanhas, áreas verdes e o mar - elementos que compõem a paisagem da cidade. Mas, qual seria o caminho? Quais trilhas seguir? Não sabíamos ao certo, Manoel de Barros nos ajudou a desfrutar o caminho, o processo. Segundo Müller (apud KISHI, 2016, p. 60), Manoel de Barros possui uma "linguagem da natureza" e por essa irmandade com as coisas e presentificação dos seres em suas obras, é que o poeta foi trazido como estímulo para nossas investigações.

Começamos construindo uma ponte. Traçamos linhas que aproximam territórios. Movemos áreas e provocamos choques. Desejávamos caminhar livres pelo mundo e experimentar diferentes referências. Queríamos transitar entre Proust e avencas, queríamos a reflexão e a intuição. Nosso intuito era construir uma ponte que se constrói com tijolos-terra, tijolos-pássaro, e também com tijolos-fundamentação, tijolos-ciência. E assim, no encontro entre prática e teoria, entre experiências sensíveis e reflexões, o trajeto parecia se anunciar mais firme para sustentar diferentes possibilidades de travessia.

Como o intuito de experimentar uma expansão mais radical dos limites da Universidade, ou das bordas que vinculam e restringem a educação ao espaço institucional apenas, o grupo organizou uma saída de campo a uma propriedade rural de produção orgânica localizada nas bordas da cidade. A seguir as experiências desse encontro com as pessoas e as coisas de lá.

\section{PALAVRA NA HORTA}

Durante o processo de criação e manutenção da horta na Universidade, ocorreu uma saída de campo a uma propriedade rural da região (Figuras 6 e 7), terra de Dona Marta, agricultora que comercializa orgânicos na cidade, e cuja filha participava conosco no Horta Teatro. Foi neste momento que a ponte, que iniciamos a construção, avançou muito. Conhecer esta senhora, que assim como nosso querido Manoel, carrega dentro de si a intimidade com o mundo vegetal, e que transborda isso em 
sua maneira de ser no mundo, renovou nosso olhar. Pudemos entender um pouco mais sobre espaço, paisagem, arquitetura, agricultura, artes e expansão do tempo, através do nosso próprio corpo, conhecimento construído pela experiência (BONDíA, 2002).

Dona Marta nos conduziu pela horta e nos apresentou seus parceiros de trabalho: brócolis, couve-flor, alface, repolho, berinjela etc. No caminho caiu uma forte chuva e seguimos nosso percurso embalados pela sensação da água que tocava a pele e tocava a terra. Um cheiro úmido brotava do chão. Alguns participantes, com suas câmeras, começaram a registrar as gotas nas folhas, nas plantas, e seguimos caminhando. Senhora da terra e das águas, Dona Marta, mal se importou com a chuva e seguiu narrando sua paisagem para nós. Após essa caminhada, ela nos ofereceu um café com bolo, que ela mesma preparou numa pequena casa que serve de depósito e suporte para o seu trabalho. Surgiram perguntas sobre o seu cotidiano, sobre o plantio, sobre a sua história. E ela nos contou um pouco de tudo. Sentimos o cheiro das hortaliças que ela cortava e amontoava em pequenos maços para a venda. Enquanto trabalhava nos contava sobre o sol, sobre as chuvas, sobre a água e sobre as relações entre o tempo e a plantação. Aprendemos enquanto víamos a chuva cair e os pássaros mudavam seus trajetos.

Foi possível perceber o que nos alerta Bessa (2016) sobre a paisagem ser um lugar privilegiado para apreender o tempo e, também, onde ocorre a sua espacialização. Nessa paisagem estava nítida a espacialização do tempo de Dona Marta. A organização da horta, a disposição das plantas, os cuidados no manejo e os caminhos percorridos todos os dias. E foi nessa paisagem, onde espaço e tempo se articulam, que aconteceram as experimentações com as poesias de Manoel de Barros (Figura 6).

Após a prosa e o café com bolo, fomos percorrer os caminhos sozinhos e em silêncio. A ideia é que cada um se movesse a partir de estímulos do meio - a partir de um som, de uma cor, de um cheiro, de um silêncio. Aos poucos uma dança era composta na intersecção entre os corpos humanos e os corpos vegetais, entre a terra e o olhar, entre os sentidos e os gestos 
que emergiam nessa paisagem sinestésica no qual estávamos imersos. Além da movimentação a partir de estímulos do ambiente, cada integrante podia ler um trecho de um poema do Manoel de Barros e podia utilizar uma máquina fotográfica, por aproximadamente dez minutos, para fazer registros que seriam posteriormente compartilhados com o grupo. Como eu vejo essa paisagem? O que eu vejo? Como exercitar um olhar que vê com o corpo todo? Esses foram alguns dos disparadores das práticas no campo.

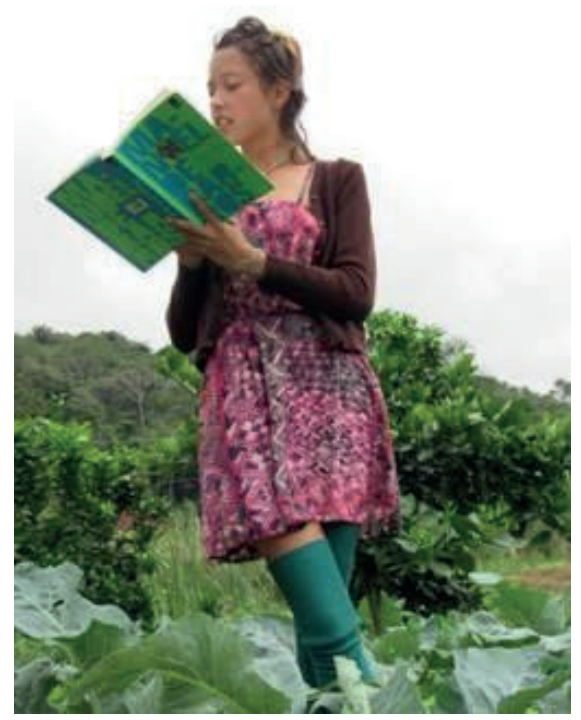

Figura 5

Fonte: Os autores (2018)

Nas experiências que aconteceram em confluência dialógica com o meio da horta orgânica, brotaram algumas composições dessa paisagem fértil. Uma delas foi o trabalho cabeça de alface (Figura 7). Trazer o elementar, terra, água, folha, raiz para 
o corpo numa experiência que nos toca e nos acontece enquanto sujeitos.

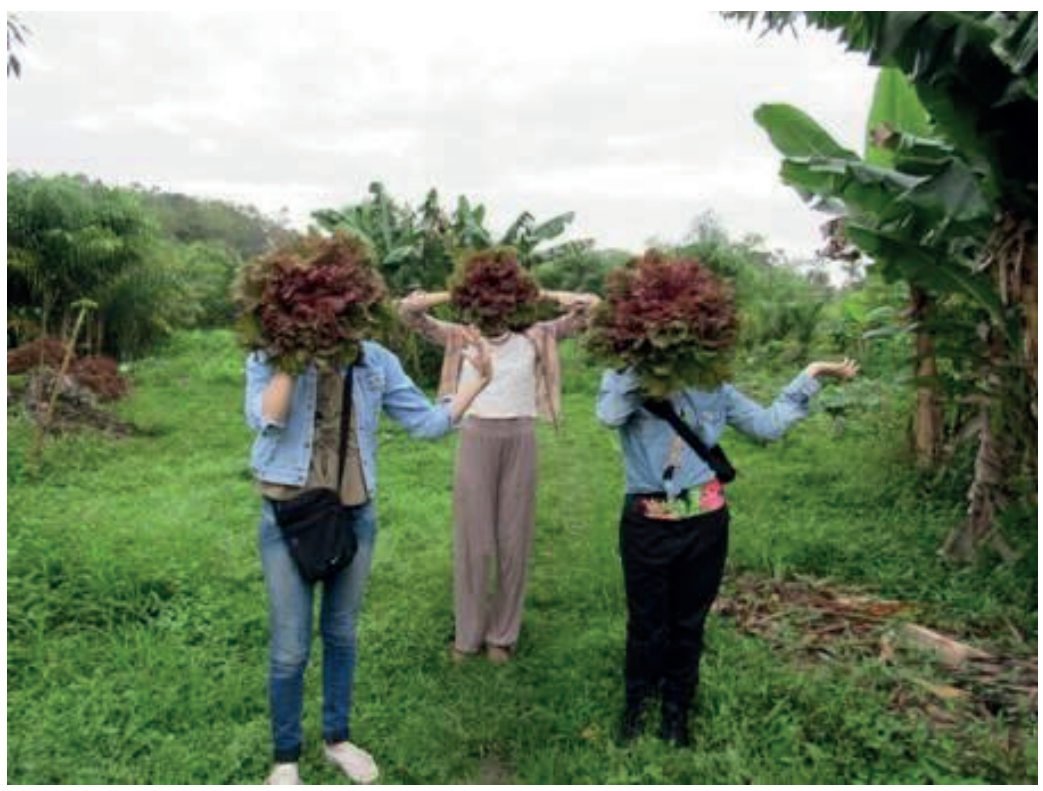

Figura 6

Fonte: Os autores (2018)

Outra composição se deu pelas palavras na forma de poesia. A partir das experiências artísticas na horta orgânica de Dona Marta, a poesia brotou. Como um organismo vivo adquiriu vida e se espacializou numa paisagem de letras.

Aqui o presente floresce

o tempo dança em gestos

ora precipita, da efemeridade cinza

ora sublima, e o corpo amanhece 


\author{
São as minhas folhaspele \\ a nutrir o silêncio do saber \\ pensamento rizomático \\ brota, da vida quer beber \\ (Autoria: integrante da Horta Teatro)
}

Algumas questões foram levantadas durante as experiências. Como o espaço que habitamos nos afeta? E como afetamos este espaço? No simples ato de tomar um café no campo, no silêncio, em meio às plantações, é estimulada em nós outra percepção de tempo e espaço. Quais os canais desses afetos e pontes comunicadoras do corpo e da paisagem? A sensibilização dos sentidos é produzida por estímulos sutis, orgânicos, pela conexão com a terra, com o vento, com a chuva, com o silêncio e com sons que agitam a paisagem. A seguir algumas considerações acerca das experiências vivenciadas e de como são semeadas.

\title{
CONSIDERAÇÕES
}

O Horta Teatro experimentou a palavra sensorial, a palavra matéria, a palavra corpo e se aproximou de experiências das quais nos fala Manoel de Barros. Quando se dá importância à presença daquilo que não tem importância para a cultura dominante, ocorre a linguagem da natureza que está presente em sua poesia (KISHI, 2016). Nesse sentido, a criação da ação coletiva apresentada no $\mathrm{FICH}$ se aproximou daquilo que Bessa nos diz a respeito da paisagem chinesa que "buscava criar sequências de ambientes e visadas que surpreendessem os usuários, distorcendo-lhes a percepção espacial" (BESSA, 2016, p. 183). Com a criação de diferentes espaços poéticos foi possível aos espectadores explorar a sociabilidade e, também, a contemplação solitária.

Assim, parece haver um diálogo entre a poesia de Manoel de Barros e o pensamento chinês antigo - que passa longe dos referenciais que hoje conhecemos da China. Para Bessa, no que diz respeito ao conceito de paisagem, o pensamento chi- 
nês o vincula ao próprio cotidiano, “[...] os chineses não estavam preocupados em alcançar o paraíso, mas em prestar atenção à natureza e às coisas" (BESSA, 2016, p. 183). O tema da natureza e a presença das coisas é evidente em toda a obra poética de Manoel. Com isso, as experiências aqui relatadas pretenderam criar aproximações entre o sensível, a experiência e a produção em arte. Construindo uma ponte entre os conhecimentos dos integrantes e a vivência dos espaços, produzindo um "saber de experiência" o qual, para Bondía, "não se trata da verdade do que são as coisas, mas do sentido ou do sem-sentido do que nos acontece" (BONDÍA, 2002, p. 27).

O que perdeu sua utilidade, esses inutensílios, caixas de feira, paver abandonados, folhas que sujam as calçadas, são as experiências que nos acontecem e não estão fatigadas de informar. É na inutilidade das coisas que encontramos o saber de experiência. Assim, segundo Müller, Manoel de Barros fala "de uma poesia que cuida daquilo que a sociedade capitalista jogou fora" (MÜLLER apud KISHI, 2016, p. 61). A construção do saber de experiência em artes em espaços esquecidos da Universidade e numa propriedade rural que cultiva alimentos orgânicos através da proposição do Horta Teatro nos fez refletir sobre práticas de arte e educação em contextos não institucionais. Experimentamos uma perspectiva de educação que prevê a ativação do sensível através de práticas que assumem o corpo, a palavra e o espaço como elementos da paisagens quando explorados pela temporalidade da experiência.

Como podemos afetar os espaços em que vivemos? Nosso corpo é também arquitetura? Como uma simples caminhada e leitura dos poemas de Manoel de Barros em uma horta fora da cidade gerou um estado tão diferente em nossos corpos? A descontinuidade do hábito corporal gera novas possibilidades de pensar e agir, gera novos estímulos, talvez novas respostas. 


\section{REFERÊNCIAS}

BARROS, Manoel de. Livro Sobre Nada. São Paulo: Record, 1996.

BESSA, Altamiro S. M.. Tempo e Paisagem. Belo Horizonte: Rev. UFMG, v. 23, n.1 e 2, p.180-195, jan./dez. 2016.

BONDÍA, Jorge Larrosa. Notas sobre a experiência e o saber de experiência. Revista Brasileira de Educação [online],n.19, p.20-28, 2002. Disponível em http://www.scielo.br/scielo.php?pid=S141324782002000100003\&script=sci_abstract\&tlng=pt]. Acesso em 05/12/2019.

KISHI, Kátia. Manoel de Barros: ver, rever e transver. São Paulo: Ciência e Cultura, vol.68, n.2, Abr./Jun. 2016. Disponível em http://cienciaecultura.bvs.br/scielo.php?script=sci_ arttext\&pid=S0009-67252016000200018. Acesso em 12/11/2019.

RINALDI, Miriam. Apontamentos sobre a técnica dos viewpoints em experimentação prática. Rebento Revista de Artes do Espetáculo, n.4, maio de 2013. Disponível em http://www. periodicos.ia.unesp.br/index.php/rebento/article/view/122/111. Acesso em 01/09/2019.

UFPR LITORAL. Projeto Político Pedagógico do Setor Litoral. Mimeo. Universidade Federal do Paraná, 2008. p. 29-32. Disponível em http://www.litoral.ufpr.br/portal/wp-content/ uploads/2015/02/PPP-UFPR-LITORAL_Set-2008_Alteracao_Dez2008.pdf. Acesso em 01/09/2019. 